D.O.I.: $10.3895 / \mathrm{S} 1808-04482008000100003$

\title{
DIFERENCIAÇÃO PARA PRESTADORES DE SERVIÇO LOGÍSTICO (PSL): UMA ANÁLISE SOBRE FATORES OPERACIONAIS
}

\section{DIFERENCES AMONG THIRD-PARTY LOGÍSTICS (3PL): ANALYSIS ABOUT OPERATIONAL FACTORS}

\author{
Mauro Vivaldini ${ }^{1}$; Fernando Bernardi de Souza ${ }^{2}$; Silvio R. I. Pires ${ }^{3}$ \\ ${ }^{1}$ Metodista University of Piracicaba - UNIMEP - Piracicaba - Brasil mvivaldini@mbbrasil.com.br \\ ${ }^{2}$ São Paulo State University - UNESP - Bauru - Brasil fbernardi@feb.unesp.br \\ ${ }^{3}$ Metodista University of Piracicaba - UNIMEP - Piracicaba - Brasil sripires@unimep.br
}

\begin{abstract}
Resumo
Esse trabalho discute os fatores operacionais que diferenciam o Prestador de Serviços Logísticos (PSL) na prestação de serviços em cadeias de suprimentos. Por meio de uma análise teórica, o estudo propõe quais seriam estes fatores. Por sua vez, numa pesquisa de campo com cinco PSLs, os autores avaliam se eles são pertinentes aos serviços prestados por estes PSLs, e se novos fatores podem ser apontados como possiveis diferenciais. Conclui-se haver uma forte relação entre a teoria estudada com a pesquisa de campo e que, mesmo sendo os fatores apresentados possíveis diferenciais, algumas empresas atuam de forma restrita por opção comercial.
\end{abstract}

Palavras-chave: Prestadores de Serviços Logísticos; Cadeia de Suprimentos; Operações logísticas.

\section{Introdução}

O Prestador de Serviços Logísticos (PSL) não pode ser visto tão somente como uma simples terceirização ou quarteirização de serviços logísticos, mas sim, como uma relação de negócio comprometido com o negócio do cliente (SAHAY, 2003; WANKE; 2004).

A absorção de diferentes tarefas pelo PSL, como disse Hoek (2001), gera impacto nos negócios pelo fato do PSL passar a atuar mais funcionalmente nas atividades operacionais da cadeia.

Realizações de atividades logísticas constituem o principal produto do PSL e, por serem inúmeras, elas tornam-se possibilidades de negócio e uma porta capaz de abrir relacionamentos com potenciais clientes. Compete a eles perceberem seu papel no fluxo da cadeia do cliente, e nele atuar buscando incorporar cada vez mais atividades.

Neste sentido, a vantagem que este provedor possui em termos de conquista de novos clientes pode estar nos diferentes tipos de atividades ou serviços que executam para a Cadeia de 
Suprimentos (CS) de seu cliente.

Considerando a importância deste provedor no mercado, é intenção deste estudo entender que fatores podem ser considerados como diferenciais operacionais no atendimento a clientes.

Para responder esta questão, o estudo busca na literatura quais poderiam ser estes fatores. Em segundo momento, avalia, na forma de uma pesquisa de campo, se estes fatores são compatíveis com que é praticado por cinco PSLs pesquisados e se outros fatores, não identificados na literatura, podem ser considerados.

Desta forma, por meio do encontro da teoria com a observação prática, este artigo procura estabelecer novos conhecimentos a respeito dos PSLs.

\section{Metodologia}

A partir de um estudo teórico sobre PSL, este trabalho propõe um conjunto de fatores que contribui para que este agente (PSL) melhor atenda a demanda de serviços existente nas diferentes CS. Estes fatores são entendidos neste estudo como diferencial operacional para o PSL atuar no mercado. Em um estudo de campo com cinco PSLs, os autores avaliam se existe correlação entre os fatores propostos pela teoria e o observado na pesquisa de campo. Além dessa análise, como contribuição o estudo apresenta outros fatores observados na pesquisa.

A Figura 1, a seguir, apresenta o modelo metodológico adotado para conduzir este estudo.

Figura 1: Modelo de metodologia da pesquisa

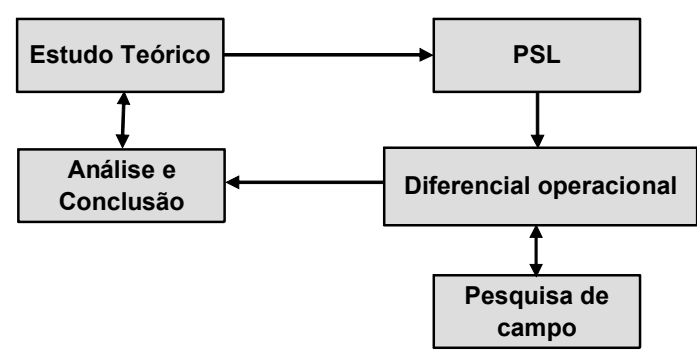

As cinco empresas estudadas foram analisadas pelos autores por cerca de seis meses. Este período permitiu aos autores entenderem não só o negócio de cada uma, bem como ajudou a avaliarem o comportamento dessas empresas diante de seus mercados de atuação. Durante a pesquisa, a interação com diversos funcionários esclareceu dúvidas e alinhou a pesquisa teórica com o que se observou na prática. Essa relação, além de ajudar os autores a entenderem as empresas, facilita a análise entre os fatores obtidos na teoria com os fatores observados nas empresas. 


\section{O Prestador de Serviços Logísticos}

A partir da análise de estudos e pensamentos de diversos autores a respeito destes provedores, este tópico discute o entendimento sobre: (1) a terceirização dos serviços logísticos, (2) a visão sobre este mercado e sua importância para a CS, bem como (3) as tendências para este segmento e (4) seu envolvimento na gestão colaborativa da CS.

\subsection{Serviços logísticos terceirizados}

Caracterizada pelas diversas transformações organizacionais, a terceirização se consolidou em diversos setores e não foi diferente na prestação de serviços logísticos. Inicialmente, a gestão de atividades logísticas estava mais focada em armazenagem e transporte, sem muita relação com os processos estratégicos da cadeia de suprimentos na busca de vantagens competitivas.

Svensson (2003) acredita que as empresas estão reduzindo o número de sub-contratados e concentrando cada vez mais atividades em um mesmo sub-contratado. No caso, isto aumenta sua dependência na cadeia e as chances de ter o PSL com um grupo maior de atividades sendo executada para uma empresa ou CS. Isto, também, reflete o pensamento de McIvor (2003), em que a terceirização deve levar em consideração a capacidade do contratado em integrar as atividades e sub-atividades contratadas.

Segundo Berglund et al. (1999), há dois direcionadores que conduzem as empresas a terceirizar: o tamanho da demanda e o tamanho da cadeia. A seguir, numa adaptação dos tópicos sugeridos por diversos autores (JAAFAR e RAFIQ, 2005; BOLUMOLE, 2001), tem-se um resumo das motivações e razões que levam uma empresa a terceirizar os serviços logísticos, bem como as possíveis razões pelas quais decidem por um parceiro:

Focar esforços em seu próprio negócio e na busca de novos mercados;

Reduzir os custos logísticos, evitando investimentos em ativos não relacionados ao negócio da empresa;

$>$ Ter uma cadeia de suprimentos complexa devido a uma base de supridores fragmentada;

$>$ Aumento do retorno de produtos;

$>$ Coordenar as atividades logísticas numa visão mais global;

$>$ Melhorar e controlar os níveis dos serviços e das atividades logísticas;

$>$ Ter maior flexibilidade e eficiência nas operações logísticas;

$>$ Ter acesso a novas tecnologias de informação e comunicação (TIC) e conhecimento logístico.

Segundo Dornier et al. (2000), os serviços logísticos se dividem em 4 diferentes tipos: serviços básicos, que não requerem grande coordenação; serviços logísticos contratuais físicos, que 
permitem a terceirização de alguns dos serviços físicos, enquanto a empresa ainda mantém controle da gestão; serviços logísticos contratuais de gestão, que subcontratam a gestão de um armazém ou frota de transporte existente; e logística contratual integrada, que incorpora serviços físicos e funções gerenciais ao operador logístico.

Ayers (2001) diz que o PSL é um instrumento de parceria na CS pelo conhecimento e infraestrutura que possui. Para Ballou (2001), em vez de possuir por completo a capacidade logística total e ter uma grande estrutura organizacional logística, algumas empresas escolhem compartilhar sua capacidade logística com outras empresas ou contratar as atividades logísticas para serem desempenhadas por empresas especializadas em fornecer tais serviços, chamados de terceiros.

O grau de terceirização varia e a atividade terceirizada difere muito pela sua complexidade. Assim, o PSL cobre da mais simples atividade até as mais sofisticadas soluções logísticas (STEFANSSON, 2005).

\subsection{O mercado de serviços logísticos e sua importância}

A logística é um elemento fundamental para o desenvolvimento de sistemas para a CS. As empresas que utilizam o PSL passam a ter nele uma figura chave para o desenvolvimento de sua CS (RAFELE, 2004).

Svenson (2003) destaca que a tendência das empresas é sub-contratar um maior número de atividades no fluxo outbound (jusante) e menor no inbound (montante), mantendo maior dependência nos processos a jusante do que a montante. Dados comprovados na pesquisa de Jaafar e Rafiq (2005) apontam cerca de $4 \%$ das contratações a montante e $52 \%$ a jusante.

Apesar dos serviços mais importantes ainda serem transporte e armazenagem, muitos outros serviços têm sido incorporados pelo PSL no intuito de atender aos clientes, principalmente de fortalecer os serviços e agregar valor à CS de seus clientes. Para Lieb e Bentz (2005), 80\% das empresas afirmam ser o PSL parte da sua estratégia na cadeia de suprimentos, bem como $70 \%$ delas consideram positivo o impacto nos custos logísticos e no nível de serviço.

Para Simchi-Levi et al. (2003), o processo de terceirização logística oferece vantagens e desvantagens. Para eles, a grande desvantagem seria a perda de controle de uma função específica por parte do contratante. Já as vantagens seriam:

Foco nas forças essenciais - a utilização de PSL permite a empresa contratante focar em competências centrais.

$>$ Oferecer flexibilidade tecnológica - à medida que a tecnologia avança, o PSL tende a atualizar seus recursos, os quais são parte de seu negócio. Já para as empresas contratantes, isso exige investimentos nem sempre disponíveis.

$>$ Outras flexibilidades - Dispor de opções geográficas para diversos serviços que o PSL pode oferecer. 
Vaidyanathan (2005) relata que o PSL com conhecimento em CS e relações globais é uma opção estratégica para oferecer soluções inovadoras em logística, no controle de inventário e na administração da demanda, encontrando melhores níveis de alocação, transporte multi-modal, armazenagem, oferta de TIC, cobertura global, e capacidade de atuar na manufatura e serviços da indústria. As empresas tendem a ganhar competitividade com serviços logísticos sob medida.

O Quadro 1, baseado em Fleury et al. (2000) e Langley e Allen (2005), permite estabelecer uma comparação dos fatores que vêm favorecendo a evolução dos PSL.

Quadro 1: Fatores que favorecem o mercado para PSL

\begin{tabular}{|l|l|}
\hline \multicolumn{1}{|c|}{ Fleury et al. (2000)} & \multicolumn{1}{c|}{ Langley e Allen (2005) } \\
- Proliferação de produtos & - Significante pressão para redução de custos \\
- Globalização & - Enfase na melhoria da CS \\
- Maior exigência de Serviços (JIT, ECR e QR) & - Significante pressão para aumentar os serviços aos \\
- Menores ciclos de vida (vestuário, eletrônica) & clientes \\
- Segmentação (clientes, canais, mercados) & - Globalização \\
& - Rápida aceleração na introdução de novos \\
& produtos \\
& - Implementação de novas tecnologias de \\
& informação \\
& - Consolidações, aquisição e fusões de empresas \\
& - Novos mercados \\
& - Problemas de segurança \\
& - Políticas governamentais \\
\hline
\end{tabular}

Fonte: FLEURY et al., 2000 e LANGLEY e ALLEN, 2005

Para Figueiredo (2005), a sofisticação dos serviços e das tecnologias oferecidas pelo PSL está atraindo muitas empresas a incluírem mais e mais atividades nos seus escopos de contratação, no intuito de aumentarem o raio de alcance dos potenciais benefícios. Por outro lado, ainda existem empresas mais comedidas no escopo de suas terceirizações, seja pelo receio de perder o controle das atividades, pela dificuldade de trocar de fornecedor posteriormente, ou ainda pela crença de que possui as competências necessárias para realizar suas atividades logísticas.

Langley e Allen (2005) destacam a importância do relacionamento entre PSL e cliente como forma de expandir os serviços. Eles apontam como expectativa dos clientes a necessidade do PSL ser mais dinâmico na oferta de tecnologia e soluções operacionais, tais como recepção de pedidos e rastreabilidade do produto.

Outro aspecto, lembrado por Lieb e Bentz (2005), é a abrangência global que o PSL tem atingido, uma vez que a expansão de negócios das grandes empresas leva consigo seus operadores. Essa abrangência exige do PSL muito mais versatilidade na oferta de serviços aduaneiros e sistema de fretes internacionais.

\subsection{A Tendência dos Serviços Logísticos}

Lieb (2005) relata que a intenção do PSL é manter seus serviços e continuar trabalhando 
como um provedor de soluções logísticas. Entretanto, a tendência dos contratos, entre PSL e clientes, tem sido a de exigir maior cobertura geográfica e mais atividades. Esse cenário é um desafio para eles. A longo prazo, a tendência deste mercado é de prover oportunidades para novas empresas de logística, voltadas a processos mais amplos, focadas na coordenação e na integração das atividades, como a 4PL (Fourth-Party Logistics - Quarteirização Logística).

Langley e Allen (2005) dizem que o PSL, por meio da incorporação de novas atividades exigidas pelo mercado, tem mudado ao longo dos anos. Este movimento demonstra progresso e caracteriza maturidade dos operadores. No entanto, os clientes pensam em ter no PSL mais habilidade para desenvolver serviços, melhorias no relacionamento, dar mais importância às informações, se envolver nas regras e conceitos de integração da CS, como também construir expertise em serviços e operações dedicadas. Também, para os autores, o mercado tende a adotar soluções advindas de empresas voltadas à coordenação logística. Isso cria as seguintes expectativas para os PSL:

Evoluir para um provedor de soluções para a CS;

Aumentar os serviços terceirizados por intermédio de um maior número de atividades (ampliar serviços aos clientes);

Melhoria contínua em tecnologia e habilidade para prover serviços necessários;

Ter foco nas necessidades dos clientes (prover soluções certas, estar envolvido nos planos de integração do cliente e entender o cliente-indústria);

Estender o relacionamento com o cliente;

Continuar adquirindo empresas e expandir os negócios;

Atuar para mercados globais;

Caminhar para soluções de coordenação logística como 4PL;

Buscar relacionamentos de longo prazo, baseados em contratos superiores a 2 anos.

Chapman et al. (2003) apontam que as organizações logísticas estão redesenhando suas estruturas e relacionamentos para facilitar e melhorar a comunicação de dados, informação e conhecimento, enquanto melhora sua coordenação, tomada de decisão e planejamento. Elas devem, principalmente, sincronizar atividades entre os agentes da CS, com o objetivo de ganhar e integrar conhecimento e operar com TIC, provendo eficiência e produtividade para a cadeia.

A presença de um PSL utilizando TIC pode contribuir para os custos das operações logísticas e favorecer a integração da CS. Esta combinação elevará o PSL a níveis mais altos de responsabilidade na cadeia, como a de um Líder Logístico ou a de um 4PL, coordenando outros PSLs e trabalhando em soluções para a CS (VAIDYANATHAN, 2005).

Para Langley e Allen (2005), o PSL evolui seu modelo de negócio para atender as expectativas dos clientes e capturar maior participação no mercado. Os modelos de negócios variam 
segundo o escopo de serviços oferecidos, a cobertura regional e o grau de colaboração na CS. Numa pesquisa sobre PSL, os autores apontam certa confusão dos respondentes em entender a transformação que vem ocorrendo neste segmento.

Ratten (2004) coloca que muitas alianças logísticas estão sendo formadas com base nas mudanças tecnológicas, na intenção de melhorar a transmissão de dados e transações. Neste caso, alianças com empresas do setor de tecnologia podem ser necessárias ao PSL. Para Bienstock (2002), o PSL deve pensar estrategicamente, em termos das regras e recursos externos de informação, para manter posição e sustentar a relação com seu cliente.

\subsection{O PSL e a Gestão Colaborativa na Cadeia de Suprimentos}

A forma mais comum de se estabelecer relacionamentos entre empresas com foco na venda do produto final tem sido contratação específica e terceirização. Neste processo, a empresa que contrata ou terceiriza precisa manter o relacionamento baseado em indicadores de desempenho operacional e custo (BOWERSOX et al., 2003).

Os indicadores podem ser uma ferramenta de equilíbrio da relação, mas, por mais que as empresas queiram o relacionamento, o objetivo idealizado pode não ser alcançado, não por incompetência, mas por razões internas ou externas às empresas. Na prática, vencer estes obstáculos é muito difícil. Isto indica que o relacionamento pode refletir situações alinhadas e desalinhadas que podem ou não ser remediadas em termos de resultados e desempenho.

Outro aspecto relacionado à terceirização pode estar no fato de que nem sempre o processo de contratação está suportado por indicadores propriamente alinhados com os objetivos das empresas. Supostamente, eles tendem a estar suportados por interesses de quem contrata, ou práticas gerenciais impróprias (LONSDALE e COX, 2000).

Estudos sobre as atividades dos PSL tendem a abordar os indicadores de desempenho relativos à operação interna do operador. Por exemplo, o estudo de Mckinnon e Ge (2004), explorando as oportunidades de transporte na cadeia de suprimentos, definem KPIs (key performance indicator) para esta atividade, comum em muitos operadores logísticos, como volume de carga ou ocupação do veículo, eficiência no consumo de combustível, tempo de utilização do veículo e outros. No entanto, não fazem menção a qualquer elo com a expectativa do cliente do operador ou de indicadores de desempenho que balizem seus prestadores de serviço.

A importância de o operador logístico ter indicadores de desempenho operacional focado em seus parceiros da cadeia, e por intermédio deles estabelecer o canal de comunicação para facilitar a relação, é o meio mais fácil e comum de implementar a colaboração na cadeia. Este método de controle do processo deve ser coordenado por Tecnologia de Informação e por sistemas de medida suportando a operação colaborativa. A efetividade operacional depende das medidas e da confiabilidade da informação entre clientes, supridores de serviço e material (BOWERSOX et al., 
2003).

Em serviços de transporte, a colaboração poderá melhorar a utilização dos equipamentos, buscando a consolidação de carga do processo a jusante e a montante, junto aos parceiros da cadeia. Isto pode ser acompanhado por meio da troca de informações sobre os planos de embarque e os recursos de transporte. O processo de embalagem é outra área potencial da colaboração. A colaboração com os centros de distribuição do PSL poderá focar uma maior produtividade através da utilização das facilidades, mão-de-obra e equipamentos.

\section{Estudo de Campo}

Este tópico considera três partes:

$>$ Os fatores que representam diferencial operacional para o PSL atender seus clientes;

$>$ Descrição e considerações a respeito das empresas estudadas;

$>$ Relação das empresas com os fatores estudados e novos fatores que influenciam no posicionamento destes agentes junto ao mercado.

\subsection{Fatores de Competitividade para o PSL}

Com base na literatura estudada, este estudo apresenta, a seguir, os fatores considerados como parâmetros para análise nas empresas estudadas.

Ter indicadores de desempenho focados nos processos operacionais da CS: atuar internamente e externamente orientado por indicadores que balizem as operações contratadas. Orientar seus contratos e serviços por meio de indicadores previamente negociados.

> Atuar no modelo 4PL ou Líder Logístico (coordenação logística na CS): poder coordenar diversas atividades por meio de diferentes prestadores de serviços.

$>$ Prestar diversas atividades (versatilidade nos tipos de serviços prestados): ter conhecimento, habilidades e estrutura operacional que suporte diversas atividades, podendo com elas oferecer ao cliente a opção de atuar somente com um PSL.

$>$ Dispor de tecnologia de informação e comunicação voltada para a CS do cliente: o volume de informações gerada pelos diferentes tipos de serviços existentes na CS exige do PSL um sistema de dados e comunicação robusto, capaz de suportar todas as interfaces e geração de informações necessárias ao seu negócio e ao negócio de seu cliente.

> Participar da CS do cliente estrategicamente: estar envolvido em desenvolvimentos de produtos, atuar nas diferentes camadas da cadeia de seu cliente, participar de campanhas etc.

> Cobertura geográfica: quanto maior a abrangência geográfica que o PSL possui, com diferentes pontos de armazenagem e cobertura em diferentes modais, maior são as possibilidades para servir os negócios de seu cliente. 
Capacidade para atuar na gestão da demanda de seu cliente: a gestão da demanda é um dos pontos mais críticos em CS. Ter visão de como cooperar nos negócios de seu cliente, bem como ter ferramentas que contribua para isso, ajuda o PSL na conquista de clientes.

\subsection{Empresas Estudadas}

As cinco empresas analisadas são PSLs que atuam no mercado há mais de 10 anos. Quatro delas passaram pelos processos de incremento de atividades ao longo dos anos, comprovando o que a teoria aponta como evolução deste segmento. Elas foram escolhidas por serem diferentes na origem, no tamanho, no faturamento e nas características operacionais e comerciais.

As empresas, cujos nomes são aqui omitidos, podem ser caracterizadas segundo a descrição a seguir:

> Empresa A - Empresa nacional situada no estado de São Paulo, com cerca de 35 funcionários, e há 11 anos atua no mercado logístico. Apesar de ter seu negócio voltado para despacho aéreo, nos últimos quatro anos tem ampliado seus serviços e operações, aproveitando a estrutura existente e o relacionamento com os clientes. Para apoiar suas operações, possui frota própria dedicada a transporte de produtos secos e frios, um galpão de armazenagem na cidade de São Paulo e operadores contratados em todas as capitais dos estados no Brasil.

Ela possui características interessantes, como o relacionamento com os clientes e a disposição em investir em ativos para servir aos clientes. No entanto, apresenta deficiência nos quesitos relacionados à formação e gerenciamento das informações e atuação com visão na demanda existente na cadeia.

Empresa B - Multinacional Norte Americana, especializada em operações dedicadas, com filiais nos EUA, Canadá e em alguns países da América Latina. No Brasil, opera há 25 anos, com cinco centros de distribuição, 430 funcionários, frota própria especializada no transporte frio e uma operação voltada ao seguimento de food-service. A avaliação dos autores o caracteriza como um prestador de serviços logístico integrado à CS de seu cliente.

Provavelmente, isto ocorre pela amplitude do processo operacional executado para seus clientes, característico do que foi discutido na teoria. Realizam muitas atividades na cadeia, tais como:

- Gestões, sendo elas: dos pedidos de venda, dos fornecedores da primeira camada (planejamento e estoque), do estoque de venda, das informações de venda e abastecimento;

- Todos os processos relacionados à armazenagem, controle de qualidade, transporte, entregas dedicadas etc.;

- Trabalham internamente com a imagem e os negócios de seus clientes, por meio de atendimento e linguagem personalizada;

- Indicadores de desempenho bem desenvolvidos baseados no negócio do cliente, tais como 
indicadores de confiabilidade e disponibilidade de produtos entregues no ponto de venda, ruptura de estoque nos centros de distribuição e nos fornecedores, atrasos nas entregas, auditorias de qualidade e de processos, desempenho de frota, produtividade das operações por funcionário, veículo etc.

Uma forte característica deste PSL é sua gestão de informações na cadeia, não só pelo fato de estar voltado para seus clientes, mas por estar bem alinhado internamente com seus objetivos. Isto caracteriza uma força marcante do processo de integração, que é a gestão da TIC.

Empresa C - Empresa nacional com administração familiar, há 34 anos no mercado, 450 funcionários, com 12 filiais espalhadas pelo Brasil, atuando com grandes clientes de diferentes seguimentos como Kraft-Foods, Sara-Lee, BSG-Continental, Parmalat e outros. Opera com transporte, armazenagem, serviços de montagem e packing, manutenção e terceirização de mãode-obra. Apesar da estrutura e diferentes atividades que executa, os autores não entendem que este PSL atue de forma integrada à CS de seus clientes, sendo muito mais um prestador de diversas atividades para diferentes clientes.

Provavelmente, isto proporciona a ele o entendimento de já ser um integrador por possuir estas características. O que difere e não contribui para que ele seja um integrador é a deficiência existente na gestão das informações. Além disso, outros fatores também não contribuem, como não ter, de uma maneira bem estabelecida, indicadores de desempenho, tanto internamente quanto externamente, não ter cultura para compartilhar os resultados, não visualizar a importância da demanda nas suas operações e, principalmente, por não ficar claro que seu comportamento operacional e comercial é pautado por ações confiáveis.

Empresa D - Grande cooperativa nacional no seguimento de transporte que ao longo dos seus 17 anos foi se profissionalizando e incorporando operações e grandes clientes. Possui 40 pontos de apoio em todo Brasil, 300 funcionários fixos, filiais com armazenagem nos estados de São Paulo, Rio de Janeiro e Paraná, e terminal de container em Santa Catarina. Apesar de seu foco principal de negócio ser o transporte, possui também armazenagem e operações dedicadas, atuando com clientes como Sadia, Perdigão, Danone, Brasken, Nestlé, Suzano Petroquímica, Firestone etc. Trata-se de uma empresa bem estruturada nas suas instalações e na administração, o que a ajuda na captação de serviços, principalmente de transporte.

Nesta empresa, dois fatores foram marcantes no processo de avaliação: um, por ser uma cooperativa e ter que atuar na gestão dos cooperados, tanto quanto na dos clientes, e outro, por ter forte característica de um grande transportador. $\mathrm{O}$ fato de possuir grandes clientes poderia facilitar uma atuação mais integrada na CS, no entanto, a distância de ações voltadas à gestão das informações, da demanda e a iniciativa comercial de buscar novas atividades prejudicam sua evolução para esta atribuição.

Empresa E - É uma empresa voltada a operações aduaneiras, atuando no apoio a muitos 
grandes clientes, como Arcor, Cabot e Flint-ink. Seu trabalho consiste não só na gestão dos processos de importação e exportação, mas em soluções de estocagem e transporte para os produtos de seus clientes. Possui 16 anos de vida, uma sede administrativa na cidade de São Paulo e 90 funcionários espalhados pelos clientes. Opera num estilo 4PL, com foco em exportação e importação, sem ter uma estrutura física própria, administrando os terceiros envolvidos diretamente neste tipo de operação. Este PSL é um operador bem focado em operações aduaneiras, possui bom conhecimento teórico do processo de integração, mas com pouca ação prática na cadeia de seus clientes. Atua à medida que é requisitado, executando operações com começo e fim, raramente são permanentes. O fato de não apresentar estrutura física operacional e tampouco ter conhecimento prático das operações prejudica uma atuação mais abrangente no mercado. Por outro lado, destaca-se pelo relacionamento, por estar bem focado nos clientes e por ter suas relações bem fundamentadas na confiança.

Apenas como observação de pesquisa, foi percebido que o conhecimento dos processos de integração e o forte envolvimento com os clientes justificam o fato deste PSL atuar no modelo sugerido por Harrison e Hoek (2003) como um 4PL, mesmo que em operações temporárias.

Numa análise mais genérica sobre o processo de avaliação das cinco empresas, algumas observações podem ser feitas:

- Todas as empresas têm a noção de que podem executar mais tarefas, ampliando o portifólio de atividades como forma de melhoria dos negócios. Entretanto, não é percebida uma relação direta disso com a possibilidade de integração dos processos na CS de seus clientes. Mesmo as maiores empresas, com uma gestão mais profissionalizada e preparada, não estabelecem estratégias de ampliação das atividades com seus clientes;

- É consenso atribuírem aos clientes à falta de iniciativa na expansão de atividades. Dizem que o cliente busca preço e execução, não gestão e resultados. Isto torna o conceito de integração e trabalho dedicado, por meio do PSL, apenas teoria;

- A atuação do PSL com os agentes de segunda camada da cadeia é muito pouco executada;

- Na empresa B, que é avaliada como agente integrador, foi observada uma gestão balizada por indicadores medindo o desempenho interno e externo. Esta característica, particularmente nesta pesquisa, permite acreditar que uma gestão orientada por indicadores de desempenho favorece a integração na CS.

\subsection{Relação dos fatores e as empresas estudadas}

Além da comparação, baseada na literatura, os autores, através das observsações da pesquisa de campo, apontam os seguintes fatores que se caracterizam como diferenciadores no modelo de gestão do PSL e podem contribuir para que ele melhore seu negócio no mercado:

$>$ Ter estrutura física, operacional e tecnológica capaz de atender a diversos clientes: 
estrutura operacional, constituída por transporte, armazém e tecnologia contribui para a conquista de clientes.

Ter foco no seguimento que atua, especializando-se em diversas atividades na CS: orientar estrutura e operação para um seguimento ajuda na especialização e contribui para atuar de forma mais focada na CS dos clientes.

Concentrar-se em grandes clientes e atuar de forma integrada ao negócio do cliente: dedicação e especialização na CS de poucos clientes podem contribuir para a abrangência de atividades e negócios nas diversas camadas da cadeia.

Investir com o objetivo de atender e ampliar os negócios com os clientes com quem já atua: demonstrar interesse pelo cliente e propor a ele soluções a partir de investimentos direcionados para o negócio dele ajuda na expansão dos negócios.

O Quadro 2 apresenta a relação entre os fatores tidos como diferenciais operacionais para o PSL, obtidos na literatura, e a observação pelos autores durante a pesquisa de campo. A análise baseia-se apenas nas observações e considerações dos autores, não havendo qualquer outro método de comprovação dos dados.

Quadro 2: Fatores de Diferenciação avaliados em PSL

\begin{tabular}{|c|c|c|c|c|c|}
\hline $\begin{array}{c}\text { Fatores de } \\
\text { Diferenciação }\end{array}$ & Empresa A & Empresa B & Empresa C & Empresa D & Empresa E \\
\hline $\begin{array}{l}\text { Indicadores } \\
\text { desempenho }\end{array}$ & $\left|\begin{array}{lllr}\text { Não } & \text { estão } & \text { bem } \\
\text { definidos } & \text { e } & \text { não } & \text { são } \\
\text { utilizados } & \text { com } & \text { clientes }\end{array}\right|$ & 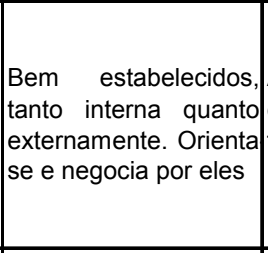 & $\begin{array}{l}\text { Ainda em } \\
\text { desenvolvimento, com } \\
\text { foco interno e sem } \\
\text { relação comercial }\end{array}$ & 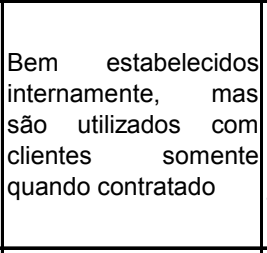 & \begin{tabular}{|lr} 
Não & possui \\
indicadores & que \\
balizem o negócio da \\
empresar & Porém, \\
cada & negócio \\
contratado pelo cliente \\
tem metas & pré- \\
estabelecidas & \\
\end{tabular} \\
\hline Modelo 4PL & $\begin{array}{lll}\text { Não possui } & \text { nem } \\
\text { estrutura } & \text { nem } \\
\text { tecnologia para } & \text { atuar } \\
\text { neste modelo } & \end{array}$ & $\begin{array}{lr}\text { Possui } & \text { estrutura, } \\
\text { tecnologia } & \mathrm{e} \\
\text { conhecimento } & \text { para } \\
\text { atuar, porém não atua }\end{array}$ & 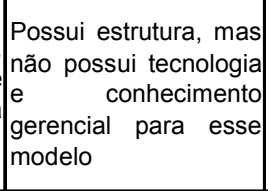 & $\begin{array}{l}\text { Possui } \\
\text { tecnologia } \\
\text { conhecimento, porém } \\
\text { possui } \\
\text { ser uma coblemas por } \\
\end{array}$ & $\begin{array}{l}\text { Sua gestão é bem } \\
\text { focada no modelo } \\
4 \mathrm{PL} \text {, porém, não } \\
\text { possui estrutura e } \\
\text { tecnologia para } \\
\text { grandes operações }\end{array}$ \\
\hline Diversas atividades & $\begin{array}{l}\text { Está mais focada em } \\
\text { transporte aério e } \\
\text { transporte rodoviário } \\
\text { local }\end{array}$ & $\mid \begin{array}{lrr}\text { Executa } & \text { diversas } \\
\text { atividades } & \text { para } & \text { um } \\
\text { grande } & \text { cliente, porém, } \\
\text { não explora } & \text { esta } \\
\text { capacidade } & \end{array}$ & $\begin{array}{l}\text { Executa diversas e } \\
\text { diferentes atividades, } \\
\text { tendo boa estrutura } \\
\text { para isso }\end{array}$ & $\begin{array}{l}\text { Mais focada em } \\
\text { transporte rodoviário }\end{array}$ & $\begin{array}{l}\text { Focada em atividades } \\
\text { aduaneiras }\end{array}$ \\
\hline $\begin{array}{l}\text { Tecnologia } \\
\text { informação } \\
\text { comunicação }\end{array}$ & $\begin{array}{|lr|}\text { Estrutura tecnológica } \\
\text { fraca para } \\
\text { abrangência maior } \\
\text { mercado } & \text { no } \\
\end{array}$ & $\mid$\begin{tabular}{lrr} 
Forte & \multicolumn{2}{c}{ estrutura } \\
tecnológica, & capaz & de \\
atender & diversos & e \\
diferentes & clientes & e \\
mercado & & \\
\end{tabular} & $\begin{array}{l}\text { Tecnologia } \\
\text { informação } \\
\text { comunicação restrita } \\
\text { às operações internas }\end{array}$ & $\left|\begin{array}{lr}\text { Tecnologia } & \mathrm{de} \\
\text { informação } & \mathrm{e} \\
\text { comunicação } & \text { restrita } \\
\text { às operações } & \text { internas }\end{array}\right|$ & $\begin{array}{l}\text { Tecnologia focada nos } \\
\text { negócios aduaneiros, } \\
\text { poucor abrangente } \\
\text { para outras operações }\end{array}$ \\
\hline Participação na CS & $\begin{array}{|lr|}\text { Restrita à } & \text { prestação } \\
\text { de } & \text { serviços } \\
\text { contratados } & \text { pelos } \\
\text { clientes } & \\
\end{array}$ & $\begin{array}{l}\text { Abrangente e bem } \\
\text { envolvida no negócio } \\
\text { do cliente }\end{array}$ & \begin{tabular}{|lr} 
Restrita à & prestação \\
de & serviços \\
contratados & pelos \\
clientes & \\
\end{tabular} & \begin{tabular}{|lr} 
Restrita à & prestação \\
de & serviços \\
contratados & pelos \\
clientes & \\
\end{tabular} & $\begin{array}{lr}\text { Restrita à } & \text { prestação } \\
\text { de } & \text { serviços } \\
\text { contratados } & \text { pelos } \\
\text { clientes } & \\
\end{array}$ \\
\hline Cobertura geográfica & Local & \begin{tabular}{|l|} 
Nacional \\
internacional
\end{tabular} & Nacional & Nacional & Local \\
\hline Gestão da Demanda & 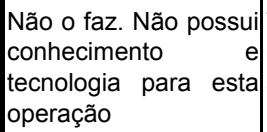 & \begin{tabular}{|lrr|} 
Tem & \multicolumn{2}{r|}{ tencologia, } \\
conhecimento & e & já \\
atua & com & esta \\
responsabilidade &
\end{tabular} & $\begin{array}{l}\text { Não o faz. Não possui } \\
\text { conhecimento r e } \\
\text { tecnologia para esta } \\
\text { operação }\end{array}$ & $\mid \begin{array}{lr}\text { Não o faz. Possui } \\
\text { conhecimento, mas } \\
\text { não tem tecnologia } \\
\text { para esta operação }\end{array}$ & $\begin{array}{l}\text { Não o faz. Possui } \\
\text { conhecimento, mas } \\
\text { não tem tecnologia } \\
\text { para esta operação }\end{array}$ \\
\hline
\end{tabular}




\section{Conclusão}

Quando se compara o processo de interpretação da literatura, em que se organizam os conceitos que fundamentam os fatores com a aplicação prática junto aos cinco PSLs pesquisados, o estudo ganha uma nova dimensão: a de fornecer o entendimento entre os fatores construídos a partir da literatura com os encontrados na prática. Neste aspecto, pode-se dizer que o estudo demonstrou coerência entre o que se obteve da teoria e o que se encontrou na prática.

Isto quer dizer que o objetivo deste estudo, de entender que fatores podem ser considerados como diferencial operacional, foi alcançado a partir do ponto em que no quadro 1 dos fatores de diferenciação pode-se perceber muitos aspectos que não são atendidos, ou que são apenas parcialmente atendidos pelas empresas.

A interpretação desta descoberta reflete dois aspectos: o primeiro, de que de fato existe uma oportunidade ao PSL para melhorar os aspectos negativos observados, segundo, a de que o PSL tem como negócio um foco de atividades ou nicho de mercado restrito. Essa conclusão se dá, especificamente, pelas características da empresa E que, ao contrário das demais, está bem focada em operações aduaneiras; por características comerciais bem definidas como no caso da empresa B, de atender operações completas em grandes clientes; e da empresa D, por ser uma cooperativa com duplo compromisso, com clientes e cooperados.

Por outro lado, pode-se dizer que o trabalho destaca a importância de este provedor estar atento às novas práticas operacionais e se preparar com sistemas que permitam oferecer serviços desta natureza.

A idéia de um PSL consciente de seu papel como agente da CS, com ação direta na melhoria de seus serviços e na importância de uma operação integrada com seu cliente, vai ao encontro dos conceitos discutidos na literatura. A atuação do PSL não pode ser individualista, ou seja, a de atuar buscando resultados isoladamente. Ele deve ter a visão de melhoria da CS de seu cliente e, por meio disso, oferecer um número de atividades e serviços que incorpore valor e novas oportunidades aos seus negócios.

\footnotetext{
Abstract

This article explores the operational factors that differentiate the third-party logistics (3PL) in the service provided in supply chains. By a theoretical analysis, the study proposes which factors are more relevant. On the other hand, through an empirical research with five 3PL, the authors evaluate if the factors studied are pertinent with the service providers by these 3PLs, and if news factors can be indicated as possible differentiate factors. It is possible to conclude that there is a strong relation between the theory and in practice observed during the empirical research and even the presented factors being possible differentials, some companies operate in a restrict way
} 
following a commercial option.

Key-words: 3PL, Supply-Chain, Logistic.

\section{Referências}

AYERS, JAMES B. Handbook Of Supply Chain Management. Flórida: CRC Press-LLC, 2001.

BALLOU, RONALD H. Gerenciamento da Cadeia de Suprimentos. Porto Alegre: Bookman, 2001.

BERGLUND, M; LAARHOVEN P.V.; SHARMAN, G.; \& WANDEL, STEN. Third-Party Logistics: Is there Future? International Journal of Logistics Management, 10, 1, p. 59, 1999.

BIENSTOCK, CAROL C. Understanding Buyer Information Acquisition for the Purchase of Logistics Services. International Journal of Physical Distribution \& Logistics Management, v. 32, n. 8, p. 636-648, 2002.

BOLUMOLE, YEMISI A. The Supply Chain Role of Third-Party Logistics Providers. International Journal of Logistic Management, v. 12, n.2, p. 87, 2001.

BOWERSOX, DONALD J; CLOSS, DAVID J; \& STANK, THEODORE P. How to master cross-enterprise collaboration. Supply Chain Management Review, Jul/Aug., p. 18-28, 2003.

CHAPMAN, ROSS L., SOOSAY, CLAUDINE, \& KANDAMPULLY, JAY. Innovation in Logistics Services and the New Bussiness Model: a Conceptual Framework. International Journal of Physical Distribution \& Logistics Management, v. 33 n. 7, p. 630-650, 2003.

DORNIER, PHLIPPE-PIERRE; ERNST, RICARDO; FENDER, MICHEL; \& KOUVELIS, PANOS. Logística e Operações Globais. São Paulo: Atlas, 2000.

FLEURY, PAULO FERNANDO; WANKE, PETER; \& FIGUEIREDO, KLEBER FOSSATI. Logística Empresarial. Coleção Coppead, São Paulo: Atlas, 2000.

HARRISON, ALAN; \& HOEK, REMKO. Estratégia e Gerenciamento de Logística. São Paulo: Futura, 2003.

HOEK, REMKO I. VAN. The Contribution of Performance Measurement to the Expansion of Third party Logistics Alliances in the Supply Chain. International Journal of Operations \& Production Management, v. 21, n. 1/2, p. 15$29,2001$.

JAAFAR, H.S.; E RAFIQ, M. Logistics Outsourcing Practices in the UK: a Survey. International Journal of Logistics: Research and Applications, vol. 8, n. 4, p. 299-312, 2005.

LANGLEY, C. JOHN JR; \& ALLEN, GARY R. Third-Party Logistics Study 2004. Results and Findings of the 2004, Ninth Annual Study. Obtido na internet www.tligatech.edu em 16/08/2005.

LONSDALE, CHRIS; AND COX, ANDREW; The historical development of outsourcing: the latest fad?" Industrial Management \& Data Systems, v. 100 n. 9, p. 444-450, 2000.

LIEB, ROBERT C. The 3 PL Industry: Where It's Been, Where It's Going. Supply Chain Management Review, set, v. 6 , p. $20-27,2005$.

LIEB, ROBERT \& BENTZ BROOKS A. The Use of Third-Party Logistics Services by Large American Manufactures: The 2004 Survey. Transportation Journal, v. 44, n. 2, p. 5, 2005.

MCIVOR, RONAN. Outsourcing: insights from the Telecommunications Industry. Supply Chain Management: An International Journal, v. 8, n. 4, p. 380-394, 2003.

MCKINNON, ALAN C. e GE, YONGLI. Use of a Synchronised Vehicle Audit to Determine Opportunities for Improving Transport Efficiency in Supply Chain. International Journal of Logistics: Research and Applications, v. 7, n. 3, p. 219-238, 2004. 
RAFELE, CARLO. Logistic Service Measurement: a reference framework. Journal of Manufacturing Technology Management, v. 15, n. 3, p. 280-290, 2004.

RATTEN, VANESSA. The Role of Learning and Information Dissemination in Logistics Alliances. Asia Pacific Journal of Marketing and Logistics, v. 16, n. 4, p. 65. 2004.

SIMCHI-LEVI, DAVID; KAMINSKY, PHILIP; \& SIMCHI-LEVI, EDITH. Cadeia de suprimento: projeto e gestão; conceitos, estratégias e estudos de caso. Porto Alegre: Bookman, 2003.

SAHAY, B.S. Supply chain collaboration: The key to value creation. Work Study, v.52, n.1, p.76-83, 2003.

STEFANSSON, GUNNAR. Collaborative Logistics Management and the Role of Third-Party Service Providers. International Journal Of Physical Distribution \& Logistics Management, v. 36, n.2, p. 76-92, 2005.

SVENSSON, GORAN. (2003), Sub-Contractor and Customer sourcing and the occurrence of disturbances in firms inbound and outbound logistics flows. Supply Chain Management: an International Journal, v. 8, n. 1, p. 41-56.

VAIDYANATHAN, GANESH. A Framework for Evaluating Third Party Logistics. Communications of the ACM, v. 48, n. 1, p. 89-94, 2005.

WANKE, PETER. Impactos da Sofisticação Logística de Empresas Industriais nas Motivações para Terceirização. Revista Gestão e Produção, v. 11, n.3, p.1-20, 2004.

\section{Autores:}

\section{Dr. Mauro Vivaldini}

Filiação institucional: Universidade Metodista de Piracicaba - UNIMEP

Departamento: Faculdade de Engenharia de Produção

Função ou cargo ocupado: Doutorando em Eng. De Produção

Endereço : Rua Pedro Cereser, 165 - Itupeva - SP - CEP 13925-000

Telefones para contato: 11-3687-2830// 11-4496-4614

e-mail:_mvivaldini@mbbrasil.com.br

\section{Dr. Fernando Bernardi de Souza}

Filiação institucional: Universidade do Estado de São Paulo - UNESP

Departamento: Faculdade de Engenharia de Bauru - Eng. Produção

Função ou cargo ocupado: Professor

Endereço : Av. Eng. Edmundo Corrijo Coube, 14-01 - Bauru - SP - CEP 17033-360

Telefones para contato: 14-3103-6122 // 16-9127-3369

e-mail: fbernardi@feb.unesp.br 


\section{Dr. Silvio R.I.Pires}

Filiação institucional: Universidade Metodista de Piracicaba - UNIMEP

Departamento: Faculdade de Administração

Função ou cargo ocupado: Professor

Endereço : Rod. do Açucar, km 156 / cx. Postal 68 - CEP 13400-911 - Piracicaba/SP

Telefones para contato: 19-3124-1515

e-mail:sripires@unimep.br 